\title{
Editorial
}

Nephrology

\section{Nail in the Coffin for Fibroblast Growth Factor 23 as a Predictor of Kidney Function Decline}

\author{
Anna J. Jovanovich ${ }^{\mathrm{a}} \mathrm{b} \quad$ Michel B. Chonchol ${ }^{\mathrm{b}}$ \\ ${ }^{a}$ Renal Section, VA Eastern Colorado Health Care System, Denver, CO, USA; ${ }^{b}$ Division of Renal Diseases and \\ Hypertension, University of Colorado Anschutz Medical Campus, Aurora, CO, USA
}

Fibroblast growth factor 23 (FGF23) is a hormone derived from bone osteocytes; it regulates circulating levels of phosphorus and active vitamin $\mathrm{D}$ (1,25 dihydroxyvitamin D). Circulating levels of FGF23 are elevated in chronic kidney disease (CKD), progressively increase as glomerular filtration rate (GFR) falls, and are the highest among individuals with end-stage renal disease (ESRD). Among individuals with CKD, FGF23 is a potent and independent predictor of ESRD, cardiovascular disease outcomes, and all-cause mortality [1]. FGF23 is also associated with adverse cardiovascular outcomes in nonCKD populations [2], which may be in part due to its likely cardiac toxicity. Indeed, FGF23 directly causes cardiomyocyte hypertrophy [3].

In kidney disease, the stimulus for FGF23 is believed to be higher serum phosphorus levels resulting from nephron loss and reduced GFR; however, this has not been proven on the molecular level, and FGF23 may also be important for calcium regulation making our understanding of the stimulus for FGF23 all the more uncertain. What is certain is that circulating FGF23 levels increase early in the course of CKD, well before other ab- normalities of mineral metabolism are noted [4], and FGF23 levels may be elevated even before any significant decrement in serum creatinine (e.g., at an eGFR of $77 \mathrm{~mL} /$ $\min / 1.73 \mathrm{~m}^{2}$ ) [4], the main clinical measure of kidney function. Because FGF23 is strongly associated with progression to ESRD among individuals with $\mathrm{CKD}$, is associated with adverse cardiovascular outcomes in non-CKD populations, and increases early in the course of CKD, the notion that FGF23 could mediate or predict kidney function decline and incident CKD among individuals with no or very mild kidney dysfunction is tempting to consider.

In this issue of the American Journal of Nephrology, Drew and colleagues report the results of a large observational study that examined the association between baseline circulating FGF23 levels and kidney function decline among 2,496 participants in the Health Aging and Body Composition Study (Health ABC Study) [5]. Glomerular filtration was estimated using cystatin $C$ because it was calibrated across all Health ABC Study samples, and because it is less influenced by age, sex, race, and muscle mass. The mean estimated GFR (eGFR) of the entire co- (c) 2018 S. Karger AG, Basel

E-Mail karger@karger.com

www.karger.com/ajn
Anna J. Jovanovich

Division of Renal Diseases and Hypertension

University of Colorado Anschutz Medical Campus

13199 East Montview Blvd, Ste 495, Aurora, CO 80045 (USA)

E-Mail anna.jovanovich@ucdenver.edu 
hort was $73 \pm 18 \mathrm{~mL} / \mathrm{min} / 1.73 \mathrm{~m}^{2}$. Twenty-three percent had an eGFR $\leq 60 \mathrm{~mL} / \mathrm{min} / 1.73 \mathrm{~m}^{2}$ and $17 \%$ had urine albumin to creatinine ratio of $\geq 30 \mathrm{mg} / \mathrm{g}$. Kidney function decline in the total cohort was defined as $\geq 30 \%$ or $\geq 3 \mathrm{~mL} /$ $\mathrm{min} /$ year reduction in cystatin C-based eGFR, and incident CKD in participants with baseline eGFR $>60 \mathrm{~mL} /$ $\min / 1.73 \mathrm{~m}^{2}$ was defined as incident cystatin C-based eGFR $\leq 60 \mathrm{~mL} / \mathrm{min} / 1.73 \mathrm{~m}^{2}$ and an eGFR decline of $\geq 1 \mathrm{~mL} / \mathrm{min} /$ year. For all analyses, FGF23 was evaluated as a continuous variable and in quartiles. In logistic multivariable regression models, which included adjustment for baseline eGFR, there was no association between higher baseline FGF23 and kidney function decline in the entire cohort. Among participants with baseline eGFR $>60 \mathrm{~mL} / \mathrm{min} / 1.73 \mathrm{~m}^{2}$, only the highest FGF23 quartile $(>60 \mathrm{pg} / \mathrm{mL})$ was significantly associated with incident CKD (incident rate ratio: 1.27; 95\% CI, 1.02-1.58). Factors hypothesized a priori to modify the relationship between baseline FGF23 and kidney function decline were evaluated using interaction terms; baseline eGFR and race did not modify any of the associations. Inflammation, assessed by baseline C-reactive protein, did not influence the relationship either - there were no changes in the ORs or incidence rate ratios when it was added to the final model. It is important to note that when FGF23 was modeled as a continuous variable, there was no significant association with incident CKD.

To determine kidney function decline, follow-up eGFR was obtained at year 3 and year 10, while FGF23 levels were assayed from samples obtained at year 2. Notably, a large proportion (43\%) of the participants had only a single follow-up eGFR measured at year 3, and 10year outcomes of these participants were not reported. Given the older age of the Health ABC Study participants (mean age of this cohort $75 \pm 3$ years), death may have been a considerable competing risk factor for kidney function decline. Furthermore, only $23 \%$ had an eGFR $\leq 60 \mathrm{~mL} / \mathrm{min} / 1.73 \mathrm{~m}^{2}$; thus, this small proportion of participants may have been insufficient to demonstrate any significant association of baseline FGF23 level and kidney function decline among those who had CKD at baseline. Moreover, even though studies show an association between FGF23 and progression of existing CKD, a single measure of FGF23 may not be sufficient to accurately predict progression of kidney function decline in CKD. A new analysis using trajectories of multiple FGF23 measures over time in the Chronic Renal Insufficiency Cohort (CRIC) demonstrates that only a certain proportion of individuals with CKD have rapidly increasing FGF23 over time and those with the steepest increase have a high risk of death [6], suggesting that only a certain subset of individuals with CKD are at high risk for adverse outcomes. It is unlikely that this functional group of Health ABC Study participants, of which only $23 \%$ had prevalent $\mathrm{CKD}$ at baseline, would include enough individuals with rapidly increasing FGF23 to demonstrate an association between FGF23 and adverse outcomes such kidney function decline.

The use of cystatin C-based eGFR and the definitions of kidney function decline employed in this analysis are commendable. Cystatin C avoids the influence of age, sex, race, and muscles mass, and it is also associated with adverse outcomes in older adults. An eGFR decline of $\geq 30 \%$ is in keeping with a recent decision by the United States Food and Drug Administration that this rate of decline is an acceptable clinical endpoint, while using an absolute eGFR decline of $\geq 3 \mathrm{~mL} / \mathrm{min} /$ year makes this study comparable to others. Nonetheless, the loss of kidney function in older adults is an area of controversy and a median rate of eGFR decline of only $1.45 \mathrm{~mL} / \mathrm{min} /$ year in the total cohort with mean baseline eGFR of $73 \pm 18 \mathrm{~mL} / \mathrm{min} / 1.73 \mathrm{~m}^{2}$ may not necessarily be pathologic [7]. Notably, FGF23 quartiles $2(36-46 \mathrm{pg} / \mathrm{mL})$ and $3(47-60 \mathrm{pg} / \mathrm{mL})$ appeared to be protective against a $\geq 30 \%$ eGFR decline compared to quartile $1(<36 \mathrm{pg} / \mathrm{mL})$.

Despite these factors, Drew et al. [5] concluded that FGF23 is a marker of kidney function but not a mediator (or predictor) of kidney function decline is appropriate. Indeed, all associations between baseline FGF23 and kidney function decline or incident CKD were either nonsignificant or substantially attenuated after adjustment for baseline eGFR, suggesting that high FGF23 was a marker of existing kidney dysfunction. Moreover, the results of their analysis agree with the results of other studies that demonstrate no substantial association between FGF23 and kidney function decline or incident CKD among individuals with no or mild baseline kidney dysfunction [8, 9]. Even though circulating FGF23 increases early in $\mathrm{CKD}$, its ability to predict kidney function decline among individuals with no or mild CKD falls short.

\section{Acknowledgments}

A.J.J. is supported by a VA Career Development Award 2 (IK2CX001030-04).

\section{Disclosures Statement}

A.J.J. reports receiving investigational drug from Shire. 


\section{References}

$>1$ Kendrick J, Cheung AK, Kaufman JS, Greene T, Roberts WL, Smits G, Chonchol M; HOST Investigators: FGF-23 associates with death, cardiovascular events, and initiation of chronic dialysis. J Am Soc Nephrol 2011;22: 1913-1922.

-2 Parker BD, Schurgers LJ, Brandenburg VM, Christenson RH, Vermeer C, Ketteler M, Shlipak MG, Whooley MA, Ix JH: The associations of fibroblast growth factor 23 and uncarboxylated matrix Gla protein with mortality in coronary artery disease: the Heart and Soul Study. Ann Intern Med 2010;152:540 648.

3 Faul C, Amaral AP, Oskouei B, Hu MC, Sloan A, Isakova T, Gutierrez OM, AguillonPrada R, Lincoln J, Hare JM, Mundel P, Morales A, Scialla J, Fischer M, Soliman EZ, Chen J, Go AS, Rosas SE, Nessel L, Townsend RR, Feldman HI, St John Sutton M, Ojo A, Gadegbeku C, Di Marco GS, Reuter S, Kentrup D, Tiemann K, Brand M, Hill JA, Moe
OW, Kuro-O M, Kusek JW, Keane MG, Wolf M: FGF23 induces left ventricular hypertrophy. J Clin Invest 2011;121:43934408.

4 Isakova T, Wahl P, Vargas GS, Gutierrez OM, Scialla J, Xie H, Appleby D, Nessel L, Bellovich K, Chen J, Hamm L, Gadegbeku C, Horwitz E, Townsend RR, Anderson CA, Lash JP, Hsu CY, Leonard MB, Wolf M: Fibroblast growth factor 23 is elevated before parathyroid hormone and phosphate in chronic kidney disease. Kidney Int 2011;79: 1370-1378.

5 Drew DA, Katz R, Kritchevsky S, Ix JH, Shlipak MG, Newman AB, Hoofnagle A, Fried L, Sarnak M, Gutierrez OM: Fibroblast growth factor 23: a biomarker of kidney function decline. Am J Nephrol 2018;47:242-250. Isakova T, Cai X, Lee J, Xie D, Wang X, Mehta R, Allen NB, Scialla JJ, Pencina MJ, Anderson AH, Talierco J, Chen J, Fischer MJ, Steigerwalt SP, Leonard MB, Hsu CY, de Boer IH,
Kusek JW, Feldman HI, Wolf M; Chronic Renal Insufficiency Cohort (CRIC) Study Investigators: Longitudinal FGF23 trajectories and mortality in patients with CKD. J Am Soc Nephrol 2018;29:579-590.

Abdulkader RCRM, Burdmann EA, Lebrao ML, Duarte YAO, Zanetta DMT: Aging and decreased glomerular filtration rate: an elderly population-based study. PLoS One 2017; 12:e0189935.

8 Isakova T, Craven TE, Lee J, Scialla JJ, Xie H, Wahl P, Marcovina SM, Byington RP, Wolf M: Fibroblast growth factor 23 and incident CKD in type 2 diabetes. Clin J Am Soc Nephrol 2015;10:29-38.

9 Rebholz CM, Grams ME, Coresh J, Selvin E, Inker LA, Levey AS, Kimmel PL, Vasan RS, Eckfeldt JH, Feldman HI, Hsu CY, Lutsey PL; Chronic Kidney Disease Biomarkers Consortium: Serum fibroblast growth factor-23 is associated with incident kidney disease. J Am Soc Nephrol 2015;26:192-200. 